\title{
Recurrent multiple cranial nerve palsies: a distinctive syndrome of cranial polyneuropathy ${ }^{1}$
}

\author{
JOHN C. STEELE ${ }^{2}$ AND ARAMASI VASUVAT \\ From the Prasat Neurological Hospital and Research Institute, Bangkok, Thailand
}

SUMMARY This report of 14 Thai patients describes the clinical features of a symptom-complex we have termed recurrent multiple cranial nerve palsies. While the disorder is common in South Eastern Asia, patients suffering similar symptoms have been seen in Europe and America. Characteristically, a long prodromal headache precedes the abrupt onset of multiple cranial nerve palsies affecting predominantly, although not exclusively, the oculomotor and facial nerves. Symptoms are self-limited and steroid therapy hastens recovery in most cases. Recurrence after many months or years is not uncommon and different cranial nerves may then be affected. Wider neurological involvement seems not to occur. Although the erythrocyte sedimentation rate is frequently elevated there is no other evidence of co-existing systemic disease. The single necropsy study thus far reported indicates that the pathogenesis of the syndrome is granulomatous inflammation of the meninges (dura), adjacent to, and involving the perineurium of cranial nerves. It is uncertain whether this inflammation is a response to a single agent, as yet unidentified, or a focal and selective hypero sensitivity reaction of connective tissue to a number of different factors. As a clinical entity the syndrome is distinctive, international, and deserving of wide recognition.

During 1967 and 1968 the authors examined many Thai patients with headache and associated multiple cranial nerve palsies. Although, in some, symptoms were due to invasive tumours of the nasopharynx, metastatic neoplasm, granulomatous meningitis, vascular lesions, or diabetes, in most there was no demonstrable intracranial cause or evidence of systemic disease. Our observations led us to conclude that there is a distinctive syndrome of cranial polyneuropathy which begins with headache followed by the abrupt onset of isolated or multiple cranial nerve palsies usually affecting the oculomotor and facial nerves. Symptoms are self limited and steroid therapy may hasten recovery. Recurrence is common after latent intervals of months or years and the same or different cranial nerves may then be involved. Wider neurological dysfunction seems not to occur and patients do not develop overt constitutional disorders.

That this syndrome is common in Eastern Asia is confirmed by conversations with Thai physicians and a report by Dr. Ratnavale in 1967 of 40 cases

${ }^{1}$ Presented at the Ninth International Congress of Neurology, New York, September 1969.

'Address for reprints: Department of Neurology, The Hospital for Sick Children, Toronto 101, Canada. seen in Ceylon. Reports of Symonds (1958) and of Hunt, Meagher, Le Fever, and Zeman (1961 indicate that the same syndrome also occurs in the Western hemisphere.

\section{PATIENTS}

In the 13 months from August 1967 to September 1968, 14 patients with the syndrome were examined at the Prasat Neurological Hospital, Bangkok, a 250 bed institution where 40,000 out-patients are seen annually and 5,000 are admitted.

The salient clinical features are summarized in Table 1. Patients ranged in age from 18 to 77 years, though the majority were in the 5th decade. There was no sex preponderance. Most were from Bangkok, though several were from the northern or southern rural areas of Thailand. One patient, case 11, had active pulmonary tuberculosis which was diagnosed one month earlier, and another, case 6 , had had an obscure illness with fever, lymphadenopathy, polyarthritis, and splenomegaly 18 months before. The remaining patients had previously been in good health and were not exposed to toxic or noxious agents. In none was there a family history of illness or neurological disorder. 
The initial symptom was invariably headache of a kind not previously experienced. It tended to be unilateral and maximum about the temple or in the eye. In the majority of patients it was constant, severe, and had been present for six hours to five months before the onset of the cranial nerve palsies.

Neurological symptoms referrable to the cranial nerves affected were usually abrupt in onset. They included blurred or double vision, drooping of the eyelid, altered facial sensation and others as one might expect. At least one of the oculomotor nerves was affected in all cases. The most common finding was of unilateral ophthalmoplegia on the painful side. Several of these patients also showed optic and sensory trigeminal nerve involvement. Lower cranial nerve palsies involving the 7th to 10th nerves occurred in four patients; in nine the distribution was unilateral and in five, bilateral (Table 1).

The natural history of the disorder is indicated by three patients who received no treatment (Table 2) and five further patients who had had neurological symptoms two months to six years before admission (Table 3). Full recovery occurred in these eight instances within three days to three months.

In all 14 patients studied a local infiltrating or mass lesion was excluded by skull radiographs and carotid arteriogram or pneumoencephalogram. In several instances the nasopharynx was biopsied. These investigations were all normal. The cerebrospinal fluid was examined in 13 cases and in six the protein content was elevated between 60 and 100 $\mathrm{mg} / 100 \mathrm{ml}$. A mild pleocytosis was present in four. In six of 10 cases tested the erythrocyte sedimentation rate (ESR) was elevated above $15 \mathrm{~mm}$ in one hour, but there was no significant abnormality of blood haemoglobin, white blood cell count, protein fractionation, latex fixation, or blood sugar. Chest radiographs were normal in 10 of 11 patients. The ESR returned to normal in two of the three cases in which it was repeated during the recovery period (Table 2).

Eleven patients received prednisone 30 to $60 \mathrm{mg}$

T A BLE 1

RECURRENT MÚLTIPLE CRANIAL NERVE PALSIES: 14 THAI PATIENTS

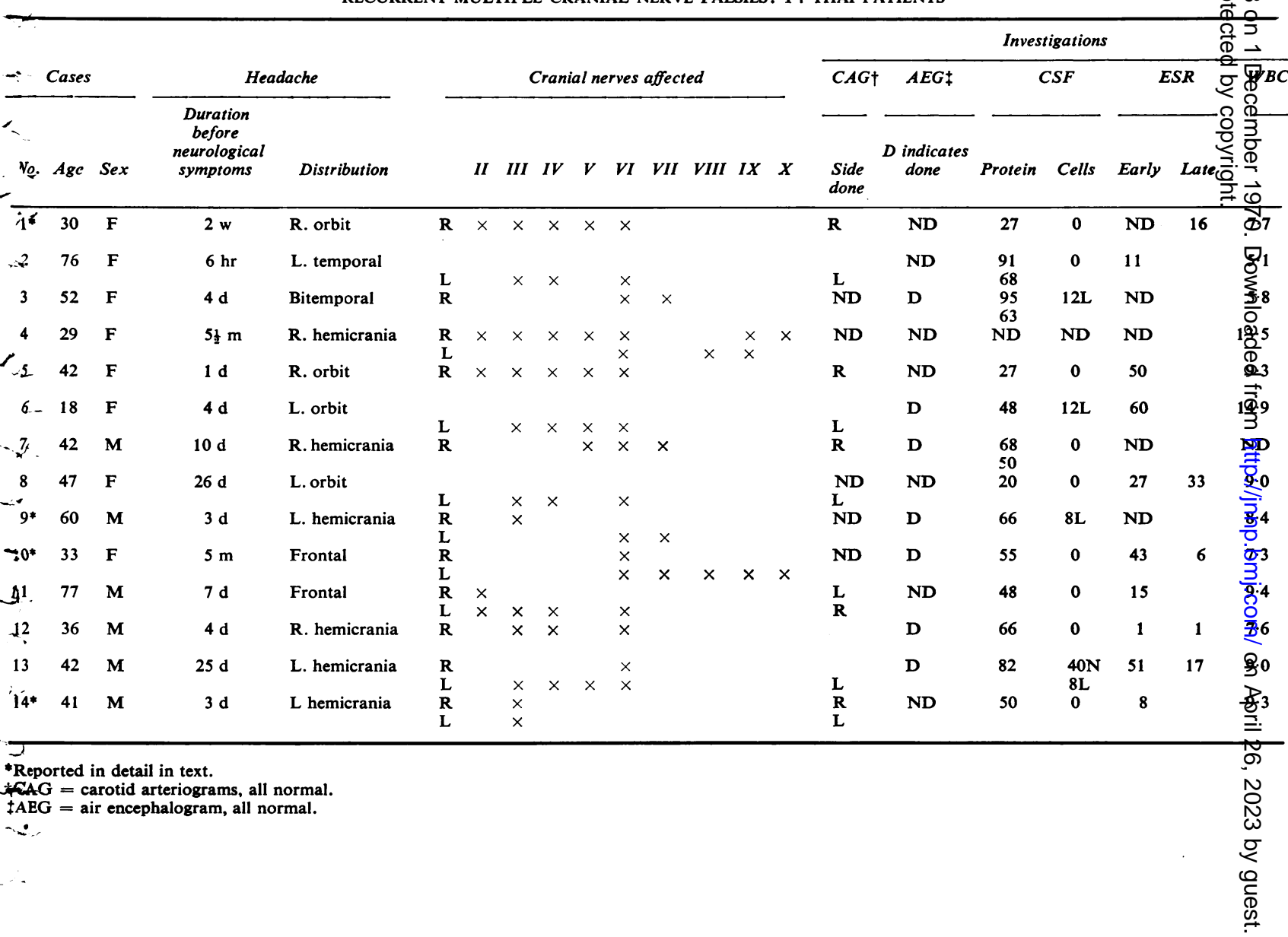


TABLE 2

RECURRENT MULTIPLE CRANIAL NERVE PALSIES

\begin{tabular}{|c|c|c|c|c|c|}
\hline Case no. & $\begin{array}{l}\text { Beginning } \\
\text { of recovery }\end{array}$ & $\begin{array}{l}\text { Interval to } \\
\text { full recovery }\end{array}$ & Relapse & Neuropathy & $\begin{array}{l}\text { Effect of } \\
\text { retreatment }\end{array}$ \\
\hline \multicolumn{6}{|c|}{ Patients treated with steroid } \\
\hline 1 & 4 days & 14 days & & & \\
\hline 2 & 4 days & 4 weeks & Two weeks after prednisone stopped & R VI & 'Slow recovery' \\
\hline 3 & None at 4 weeks & - & & & \\
\hline 4 & Spontaneous & 20 days & & & \\
\hline 5 & 5 days & 9 days & & & \\
\hline 6 & 1 day & 6 days & At 6 months & L optic neuritis & Recovery 1 week \\
\hline & & & At 12 months & L III V & Recovery 2 months \\
\hline & & & At 18 months & L III VI & Recovery 2 months \\
\hline 10 & At 8 weeks & & & & \\
\hline 11 & None at 6 weeks & & & & \\
\hline 12 & 2 days & \multicolumn{2}{|l|}{30 days (partial) } & & \\
\hline 13 & 4 days & \multicolumn{2}{|l|}{14 days } & & \\
\hline 14 & 6 weeks & \multicolumn{2}{|l|}{8 weeks } & & \\
\hline \multicolumn{6}{|c|}{ Patients not treated with steroid } \\
\hline 7 & None at 6 weeks & \multicolumn{2}{|l|}{8 davs } & & \\
\hline 8 & 14 days & \multirow{2}{*}{\multicolumn{2}{|c|}{$\begin{array}{l}8 \text { days } \\
3 \text { weeks }\end{array}$}} & & \\
\hline 9 & None for 2 months & & & & \\
\hline
\end{tabular}

TABLE 3

RECƯRRENT MULTIPLE CRANIAL NERVE PALSIES: ANTECEDENT SYMPTOMS IN FIVE PATIENTS

\begin{tabular}{clc}
\hline Case no. & \multicolumn{3}{c}{ Symptoms before admission } \\
\cline { 2 - 3 } & \multicolumn{1}{c}{ First attack } & $\begin{array}{c}\text { Interval } \\
\text { between } \\
\text { pre-admission } \\
\text { attacks }\end{array}$ \\
\hline 2 & $\begin{array}{l}\text { Headache, blurred vision for 3 days } \\
\text { Weakness of jaw and trouble swallowing } \\
7\end{array}$ & $\begin{array}{l}\text { Right hemicrania, diplopia, drooping right } \\
\text { mouth for one month } \\
\text { Right hemicrania and diplopia for } 3\end{array}$ \\
12 & $\begin{array}{l}\text { 2 months } \\
\text { months } \\
\text { Right hemicrania, right ptosis }\end{array}$ & 2 years \\
14 & & $\begin{array}{l}6 \text { years } \\
3\end{array}$ \\
\hline
\end{tabular}

per day. In seven of these improvement began within four days and in six was complete by one month. In the other recovery was incomplete at six weeks. One patient, who did not respond to treatment for six weeks, recovered two weeks later. Three patients were unimproved during the one to two months they were observed. The variable natural course of the disease makes accurate assessment of the response to steroid therapy difficult and somewhat subjective. In several instances prednisone dramatically relieved headache and improved neurological signs; in others it seemed to hasten recovery. There were several cases, however, in which steroid therapy had little effect. Symptoms recurred in two patients two weeks and six months after stopping prednisone (Table 2).

The following four case histories illustrate features of the syndrome.
CASE 1

For one year a 30 year old farm worker had had intermittent generalized headache. Two weeks before admission she experienced severe right hemicrania which was maximal in the eye; 12 days later diplopia and then rapid failure of vision in the right eye developed. On examination, the visual acuity was reduced to finger counting on the right, though it was $20 / 20$ on the left. The optic fundi were normal. Total right 6th nerve palsy and 3rd nerve paresis with ptosis, pupillary dilatation, and moderate impairment of ocular movement were found. Sensation was diminished in the area supplied by the first division of the right trigeminal nerve. Investigation, including right carotid arteriography, was normal. Blindness in the right eye and total ophthalmoplegia developed during the next seven days. At that time prednisone $40 \mathrm{mg}$ per day was begun. Her vision began to return four days later and by 18 days the only abnormality remaining was a minor weakness of the right lateral rectus muscle. Steroids were gradually reduced during the next four weeks.

COMMENT Unilateral ophthalmoplegia was associated with impairment of visual acuity and hypoaesthesia in the area supplied by the first division of the trigeminal nerve on the same side. Prednisone produced improvement which began on the fourth day, and was complete by the 18 th.

\section{CASE 9}

A 60 year old merchant developed frontal headache and three days later had diplopia. Though his headache continued, the diplopia subsided in several days. When examined one month later there was a partial left 6th nerve palsy. Mild ptosis of the right eyelid, slight limitation of medial movement of the right eye, dilatation of the pupil indicated a right 3rd nerve paresis. An air 
encephalogram and the cerebrospinal fluid findings were normal. During the next three weeks his headache was predominantly left sided and a left facial palsy developed. At this time the cerebrospinal fluid contained 8 lymphocytes and $66 \mathrm{mg} / 100 \mathrm{ml}$. protein. During the subsequent three weeks slow and progressive recovery occurred.

COMMENT Headache and bilateral oculomotor palsies were present for two months. During this time a 7th nerve palsy developed. Recovery was complete in three weeks. The patient received no treatment.

\section{CASE 10}

A 33 year old labourer from northern Thailand had had intermittent generalized headache for several months. Five months before admission the pain became a constant and frontal ache. Shortly thereafter she began to experience episodes of vertigo. Two weeks before admission to hospital the left angle of her mouth drooped, her headache became more severe and was centred in the right eye. Examination revealed 6th nerve palsies and dysfunction of the left lower cranial nerves as indicated by facial weakness, minor nerve type deafness, impairment of palatal sensation, and deviation of the palate to the right with phonation. Neurological and general examination were otherwise normal. The ESR was $43 \mathrm{~mm}$ in one hour. Tests of haemoglobin, white blood cell count and serum protein, blood urea nitrogen, and blood sugar were normal, as was a pneumoencephalogram and the cerebrospinal fluid. During the first two weeks in hospital her headache subsided and hearing in the left ear improved spontaneously. An audiogram at this time was normal. The other cranial nerve palsies persisted. Three weeks after admission prednisone $40 \mathrm{mg}$ per day was begun and continued for two months. Her clinical condition did not change. The ESR towards the end of the period of treatment was $6 \mathrm{~mm}$ in one hour.

COMMENT Multiple unilateral lower cranial nerve palsies occurred together with bilateral 6th nerve palsies. The headache, mild deafness and vertigo disappeared spontaneously within two weeks of admission to hospital but the other palsies persisted. Prednisone produced no further improvement during the next two months.

\section{CASE 14}

In 1965 a 38 year old dispenser had had intermittent headache for two months and drooping right eyelid for five days. He had a right 3 rd nerve palsy, but the pupils were equal in size. At that time he received prednisone $30 \mathrm{mg}$ per day and six days later began to improve. By the 17th day he had recovered completely. He remained well then for three years at which time he developed left hemicrania and several days later drooping of the left eyelid. When examined on admission he was found to have a total left 3 rd nerve palsy. The pupil was widely dilated and unresponsive to light. Examination was otherwise negative. Carotid arteriograms and the cerebrospinal fluid were normal. He received prednisone $60 \mathrm{mg}$ per day but, despite this, there was no change in the 3rd nerve palsy until six weeks after the onset. Full recovery then occurred over the next two weeks.

COMMENT The patient experienced a right 3 rd nerve palsy and three years later a left 3rd nerve palsy. In the first episode there was prompt recovery with prednisone treatment; in the second recovery did not begin for 6 weeks despite treatment with steroid.

\section{DISCUSSION}

At the second Asian and Oceanic Neurological Congress of 1967 Dr. G. S. Ratnavale, of Colombo, described 40 Ceylonese patients with cranial polyneuropathy. Headache, low grade fever, malaise, and weight loss frequently preceded the onset of neurological symptoms by several months. While any of the motor and sensory cranial nerves might be affected, involvement of the 7th and oculomotor nerves was most common. In some the palsies were unilateral and restricted but in others widespread, discontinuous, and bilateral. Although some patients complained of mild sensory symptoms in the limbs, in none was there clear clinical evidence of neuropathy. Careful investigation failed to indicate clinical or radiological evidence of sarcoidosis or active tuberculosis. The ESR tended to be elevated and the cerebrospinal fluid frequently showed pleocytosis and raised protein. All cases received prednisolone 15 to $60 \mathrm{mg}$ per day and improvement usually began within 10 days. At follow-up, a certain unspecified number of patients had relapsed and cranial nerve palsies and non-specific constitutional symptoms recurred.

Obviously this syndrome is common in Eastern Asia, but it is not unique to this region as is indicated by two important observations from the Western Hemisphere.

Symonds in 1958 reported on four patients with a succession of multiple and disseminated cranial nerve palsies of rapid onset and short duration occurring at irregular intervals over a period of several years. Both upper and lower motor cranial nerves were involved. Headache was a prominent feature. One patient had active tuberculosis and another is likely to have suffered from sarcoidosis. The two remaining patients had symptoms intermittently which suggested a constitutional disorder. Symonds felt they represented a distinct clinical entity and were a consequence of a selective hypersensitivity reaction which was not specific for any single cause.

In 1961 Hunt and co-workers reported six cases from the United States who suffered a syndrome of focal cranial polyneuropathy featured by recurrent unilateral retro-orbital pain with ocular palsy, hypoaesthesia in the area supplied by the first 
division of the trigeminal nerve, and occasional blindness. Headache or eye pain preceded the ophthalmoplegia, symptoms lasted from several days to weeks, spontaneous remission occurred, and attacks recurred at irregular intervals over several years. In none of these patients was there evidence of a constitutional disorder. In support of their belief that these symptoms were due to a self-limiting inflammation of the cavernous sinus, Hunt et al. (1961) cited a 1954 report by Eduardo Tolosa of a patient with recurrent painful ophthalmoplegia who died three days after intracranial exploration. Neuropathological studies revealed a low-grade non-specific granulomatous infiltration of the dura mater forming the lateral wall of the cavernous sinus.

Further articles have confirmed Hunt's clinical observation. Smith and Taxdal (1966) emphasize that the clinical entity, 'painful ophthalmoplegia', is probably not uncommon, for in seven months they saw five such patients. Anders Øther (1967) of Denmark and Hedges (1965) of Philadelphia also report individual cases in which a degree of proptosis and chemosis was associated with the ophthalmoplegia.

Our cases and those of Ratnavale (1968) are similar to those of Symonds (1958) and Hunt et al. (1961) and relate the two. Thus, while a focal cranial neuropathy with ophthalmoplegia is usual, lower cranial nerve involvement does occur. Motor nerves are mainly but not exclusively affected, for there may be trigeminal hypoaesthesia, vertigo, and deafness. Other overt radicular or peripheral nerve dysfunction does not seem to occur.

As Hunt et al. (1961) and Tolosa (1954) suggest, the pathogenesis of the disorder seems likely to be a granulomatous inflammation of the meninges adjacent to and involving the perineurium of individual or groups of cranial nerves. The symptoms indicate that this is focal in some cases and disseminated and multiple in others. When considering the aetiology of the condition, we must take into account the benign self-limiting expression of the syndrome, its focal manifestation, its tendency to recur, and the geographical distribution. Whether the syndrome is a distinct disease due to the direct effect of a single agent, as yet unidentified, or whether it is a specific and local hypersensitivity reaction to various agents remains to be determined. The value of steroid therapy is likely to be related to its antiinflammatory effect.

The differences which exist between this syndrome and that of multiple cranial nerve dysfunction which occurs in the Guillain-Barré syndrome should be emphasized (Munsat and Barnes, 1965). This differentiation is clinical, since the exact aetiological mechanisms of both disorders remain uncertain. In the syndrome we are describing a long prodromal headache is usual, symptoms do not follow a systemic illness, and wider neurological dysfunction does not occur. The cerebrospinal fluid protein is only mildly elevated and accompanying pleocytosis is common. Both disorders are self-limiting in their clinical expression but, while recurrence is usual in this form of cranial polyneuropathy, it is infrequent in the Guillain-Barré syndrome.

\section{REFERENCES}

Hedges, T. R. (1965). Alternating exophthalmos with painfu ophthalmoplegia. Arch. Ophthal., 74, 625-627.

Hunt. W. E., Meagher, J. N., Le Fever, H. E., and Zemañ W. (1961). Painful ophthalmoplegia-its relation to क indolent inflammation of the cavernous sinus. Neurolog (Minneap.), 11, 56-62.

Munsat, T. L., and Barnes, J. E. (1965). Relation of multiple cranial nerve dysfunction to the Guillain-Barré syndrome J. Neurol. Neurosurg. Psychiat., 88, 115-120.

Øther, A. (1967). Painful ophthalmoplegia: report of a case. Acta ophthal. (Kbh.), 45, 371-373.

Ratnavale, G. S. (1968). Cranial polyneuritis,-A distinct clinical entity. Proc. Aust. Ass. Neurol., 5, 527-529.

Smith, J. L., and Taxdal, D. S. R. (1966). Painful ophthalmoplegia. The Tolosa-Hunt syndrome. Amer. J. Ophthal., 61, 1466-1472.

Symonds, Sir Charles (1958). Recurrent multiple cranial nerve palsies. J. Neurol. Neurosurg. Psychiat., 21, 95-100.

Tolosa, E. (1954). Periarteritic lesions of the carotid siphon with the clinical features of a carotid infraclinoidal aneurysm. J. Neurol. Neurosurg. Psychiat., 17, 300-302. 